\title{
Cardiovascular Risk and Disease Among Masters Endurance Athletes: Insights from the Boston MASTER (Masters Athletes Survey To Evaluate Risk) Initiative
}

Kayle Shapero ${ }^{1,2 \dagger}$, James Deluca ${ }^{2 \dagger}$, Miranda Contursi ${ }^{2}$, Meagan Wasfy ${ }^{2}$, Rory B. Weiner ${ }^{2}$, Gregory D. Lewis ${ }^{2}$, Adolph Hutter ${ }^{2}$ and Aaron L. Baggish ${ }^{2^{*}}$

\begin{abstract}
Background: Masters athletes (MAs), people over the age of 35 that participate in competitive sports, are a rapidly growing population that may be uniquely at risk for cardiovascular (CV) disease. The objective of this study was to develop a comprehensive clinical CV profile of MA.

Methods: An electronic Internet-based survey (survey response rate $=66 \%$ ) was used to characterize a community cohort of MAs residing in Eastern Massachusetts, USA. Clinical and lifestyle factors associated with prevalent CV disease were determined using logistic regression.

Results: Among 591 MAs (66 \% men, age $=50 \pm 9$ years) with $21.3 \pm 5.5$ years of competitive endurance sport exposure, at least one $\mathrm{CV}$ risk factor was present in $64 \%$ including the following: family history of premature atherosclerosis (32\%), prior/current tobacco exposure (23\%), hypertension (12.0\%), and dyslipidemia (7.4\%). There was a $9 \%$ (54/591) prevalence of established CV disease which was accounted for largely by atrial fibrillation (AF) and coronary atherosclerosis (CAD). Prevalent AF was associated with years of exercise exposure [adjusted odds ratio, $\mathrm{OR}(95 \%$ confidence intervals); $\mathrm{OR}=1.10(1.06,1.21)]$ and hypertension $[\mathrm{OR}=1.05(1.01,1.10)]$ while CAD was associated with dyslipidemia $[O R=9.09(2.40,34.39)]$ and tobacco use $[O R=1.78(1.34,3.10)]$ but was independent of exercise exposure.

Conclusions: Among MAs, AF is associated with prior exercise exposure whereas CAD is associated with typical risk factors including dyslipidemia and prior tobacco use. These findings suggest that there are numerous opportunities to improve disease prevention and clinical care in this population.
\end{abstract}

Keywords: Exercise, Masters athlete, Sports cardiology, Cardiovascular risk factors

\section{Key Points}

1. Approximately two thirds of community-based masters athletes have at least one established traditional cardiovascular risk factor with a family history of premature atherosclerotic disease and

\footnotetext{
* Correspondence: abaggish@partners.org

†Equal contributors

${ }^{2}$ Cardiovascular Performance Program, Massachusetts General Hospital, 55

Fruit Street, Yawkey Suite 5B, Boston, MA 02114, USA

Full list of author information is available at the end of the article
}

prior tobacco exposure identified as the most common issues.

2. Among community-based masters athletes, the estimated prevalence of established cardiovascular disease is a proximally $10 \%$ and is accounted for almost exclusively by atrial fibrillation and atherosclerotic coronary artery disease.

3. Approximately one in seven masters athletes experience dissatisfaction with the healthcare system due in part to care providers' tendency to dismiss complaints due to their status as athletes. 


\section{Background}

While habitual exercise reduces the risk of cardiovascular (CV) disease, it does not confer complete immunity $[1,2]$. Masters athletes (MAs), men and women over the age of 35 who participate in organized competitive sport, are a rapidly growing segment of the population that are increasingly common in clinical practice [3]. Atherosclerotic coronary artery disease (CAD) is the most common cause of sudden death among MAs [4], and recent data suggest that MAs may be at higher risk for CAD than their otherwise similar sedentary counterparts $[5,6]$. In addition, emerging data demonstrate associations between other forms of $\mathrm{CV}$ disease including atrial fibrillation (AF) and nonischemic myocardial fibrosis and exercise exposure in excess of low to moderate levels [7, 8]. However, lifestyle characteristics, CV risk factors, and their relationships with established CV disease among MAs remain incompletely understood.

To address this knowledge gap, we undertook the present study. Specifically, we utilized an Internet-based survey tool to collect demographic, lifestyle, and medical information from an unselected, community-based population of MAs. The primary goal of this initiative was to develop a comprehensive clinical profile of the contemporary MA with an emphasis on the relationship between $\mathrm{CV}$ risk factors and established disease.

\section{Methods}

\section{Survey Design}

The Boston Masters Athletes Survey To Evaluate Risk (MASTER) study utilized a web-based survey tool to collect data across complementary areas of interest in an effort to characterize a representative sample of MAs. The survey was comprised of 57 questions pertaining to demographics $(n=8)$, lifetime exercise exposure and dietary habits $(n=14)$, traditional $\mathrm{CV}$ risk factors $(n=$ $11)$, personal health history $(n=12)$, and healthcare utilization and satisfaction $(n=12)$. The content, wording, and ordering of each survey question were designed to address issues of relevance as determined by a comprehensive literature search using the following keyword search terms: "masters athlete," "older athlete," "risk factors," "cardiovascular risk factors," and "cardiovascular disease," and by aggregate clinical experience of the investigative team. Contents of the final survey were formatted for use in LimeSurvey (http://www.limesurvey.org, copyright (c) 2005), an open-source, fully customizable software package designed for research, clinical, academic, and operational data collection. Data defining survey content and participant responses were stored on Secure Sockets Layer (SSL)-encrypted servers maintained by Partners Healthcare's Discovery Informatics Platform for Research (Newton, MA). All aspects of the survey, recruitment protocol, and analytic plan were approved by the Partner's
Human Research Committee. The study complied with the Declaration of Helsinki, and informed consent was obtained from each subject prior to beginning the survey.

Standardized definitions of CV risk factors were stipulated in the survey as follows. Hypertension was defined as the documentation of either a systolic blood pressure $\geq 140 \mathrm{mmHg}$ or a diastolic blood $\geq 90 \mathrm{mmHg}$ by a clinician on at least two occasions or ongoing use of one or more antihypertensive medications [9]. Dyslipidemia was defined as the laboratory-based documentation of a lowdensity lipoprotein level $\geq 160$ on at least two occasions or ongoing use of one or more antihypertensive medications [10]. Prior tobacco use was defined as the previous daily use of a smokable or chewable tobacco product for $>2$ years. A significant family history of atherosclerosis was defined as the development of atherosclerotic CAD or death from $\mathrm{CV}$ disease in a first-degree relative prior to age 55 (males) or 65 (females). Similarly, established $\mathrm{CV}$ diseases were defined in the following standardized fashion. Atherosclerosis was defined by prior acute coronary syndrome, stroke, stable or unstable angina, or coronary/peripheral arterial revascularization. Arrhythmia was defined by the presence of one of the following: (1) second-degree, type 2, or complete heart block, (2) chronic persistent or paroxysmal AF or atrial flutter, or (3) an alternative sustained supraventricular or ventricular tachycardia as documented by 12-lead ECG, ambulatory rhythm monitoring, or hospital-based telemetry on at least one occasion. Valvular disease was defined as the prior echocardiographic documentation of stenosis or regurgitation of moderate or greater severity or a prior valve repair/replacement procedure.

\section{Survey Sample}

Publically available, web-based search engines and the authors' a priori knowledge of local organizations were used to identify MA clubs in the Greater Boston, MA, USA, area. We defined MA clubs as any publically advertised organization designed to facilitate sport-specific exercise training for older athletes with emphases on individual performance and/or team competition. Our geographic catchment area was limited both to the state of Massachusetts and to an 80-mile radius from central Boston. Following these criteria, we identified 28 eligible groups (Fig. 1). The chief administrative officer from each club was personally contacted via an introductory email that was used to delineate the goals of the survey and to determine general club interest in participation. Follow-up telephone correspondences were arranged on an individual basis as requested by the club's chief administrative officer. Nonresponding club leaders were contacted a second time by email and/or telephone and were encouraged to participate. Of the 28 eligible clubs, 18 representing the following specific athletic disciplines: 


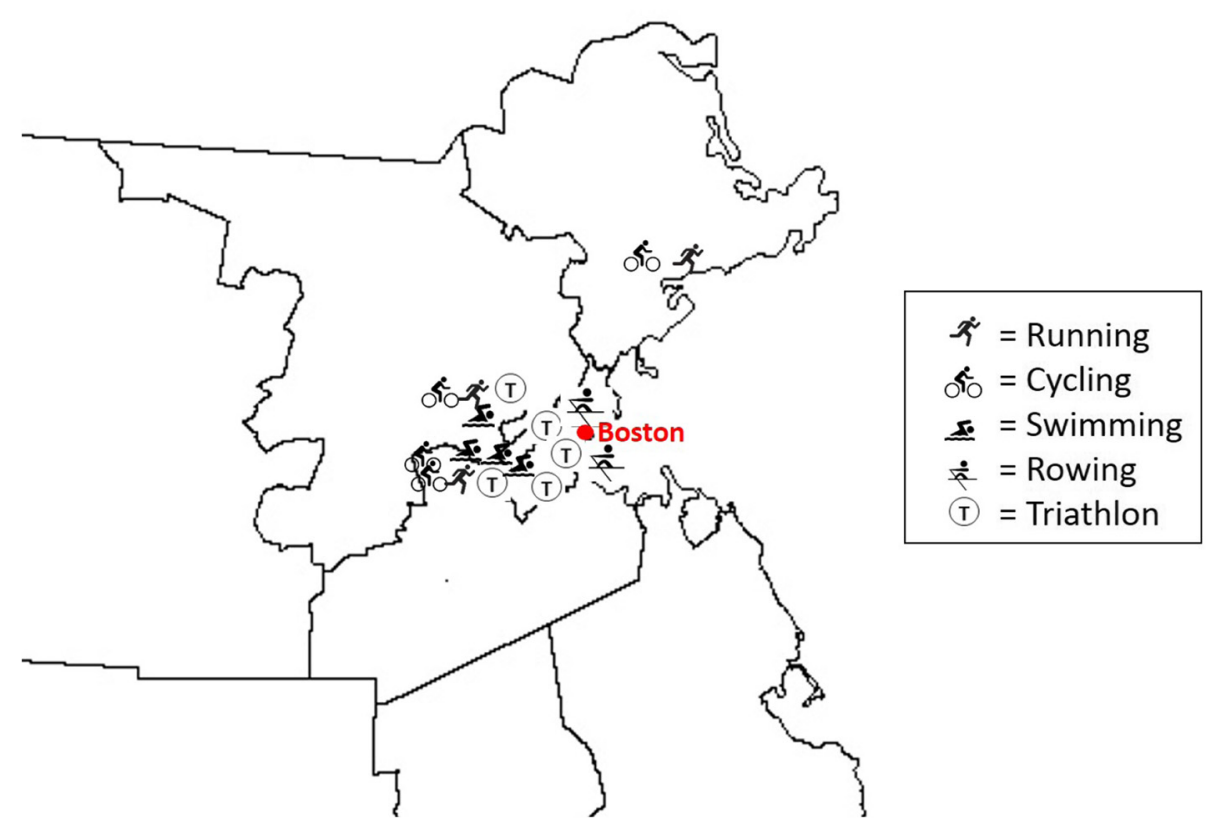

Fig. 1 Geographical distribution of responding masters athlete organizations. Each of the 18 running, cycling, swimming, rowing, and triathlon teams who responded and agreed to disseminate the survey among their members are represented

running $(n=3)$, cycling $(n=4)$, swimming $(n=4)$, rowing $(n=2)$, and triathlon $(n=5)$, ultimately confirmed willingness to participate. The 10 clubs that declined to participate represented the following sporting disciplines: running $(n=4)$, cycling $(n=2)$, rowing $(n=2)$, and triathlon $(n=2)$, and were all contained within the geographic catchment displayed in Fig. 1. Within the clubs that agreed to participate, the survey tool was distributed to 739 potential participants, which served as the source pool from which the final study sample was derived.

\section{Survey Administration}

Each participating club agreed to universally disseminate study-related information via member email distribution lists to official club members. Between July 2014 and October 2014, athletes belonging to one of the clubs described above received an introductory letter via email along with a secure link to the electronic survey. The survey was accessible for a 6-week time period. Participants were asked to complete the survey in its entirety but were permitted to do so in multiple sittings to facilitate confirmation of data in cases where medical record reviews or contact with personal physicians were required. Complete participant anonymity was maintained as per the commercially available software that is designed to keep all identifying information including respondents IP addresses shielded from investigators. Submitted surveys that were less than $95 \%$ complete and those that were filed by athletes under the age of 35 were excluded from the final database.

\section{Statistical Analysis}

Data were manually extracted from the survey tool into Excel spreadsheets. Continuous variables are presented as means \pm standard deviations and categorical variables as fractions. Gender-based comparisons were made using two-tailed unpaired $t$ tests, chi-squared tests, or Fischer's exact test as appropriate for data distribution. Univariate and multivariate logistic regression were used to determine factors associated with prevalent atherosclerotic CAD and cardiac arrhythmia. Factors with a univariate $p$ value of less than 0.10 were tested in forward step-wise multivariate logistic regression analyses to identify independent predictors of these two forms of CV disease (Table 5). Reported odds ratios (ORs) reflect risk as dictated by the binary presence of selected dependent variables (i.e., established hypertension vs. no hypertension) or per year in the context of the dependent variable "years of exercise exposure." Analyses were performed with the use of SPSS software (version 21, IBM). A $p$ value of $<0.05$ was considered significant.

\section{Results}

\section{Baseline Demographics}

The survey tool was sent to 739 athletes with a final sample yield consisting of 591 participants (men, $n=$ 391; $66 \%)$. Attrition was accounted for by incomplete survey data $(n=32)$ and failure to reply to the invitation to participate $(n=116)$. Demographics for the total sample and as stratified by gender are shown in Table 1. Compared to female participants, men were significantly 
Table 1 Baseline demographics

\begin{tabular}{|c|c|c|c|c|}
\hline & Total & Men $(n=391)$ & Women $(n=200)$ & $p$ value \\
\hline Age, years & $50 \pm 9$ & $51 \pm 9$ & $48 \pm 9$ & 0.001 \\
\hline Height, cm & $174.8 \pm 13.7$ & $179.3 \pm 11.2$ & $165.9 \pm 13.7$ & $<0.001$ \\
\hline Weight, kg & $72.9 \pm 13.0$ & $78.6 \pm 10.7$ & $61.9 \pm 9.8$ & $<0.001$ \\
\hline Body mass index, $\mathrm{kg} / \mathrm{m}^{2}$ & $23.4 \pm 3.6$ & $22.4 \pm 2.8$ & $24.0 \pm 3.8$ & $<0.001$ \\
\hline \multicolumn{5}{|l|}{ Marital status } \\
\hline Married/committed relationship & $490 / 591(82.9)$ & $349 / 391(89.3)$ & $141 / 200(70.5)$ & $<0.001$ \\
\hline Single & $52 / 591(8.8)$ & $24 / 391(6.1)$ & $28 / 200(14.0)$ & 0.001 \\
\hline Divorced & $47 / 591(8.0)$ & 18/391 (4.6) & $29 / 200(14.5)$ & $<0.001$ \\
\hline Children & $426 / 591(72.1)$ & $314 / 391(80.3)$ & $112 / 200(56.0)$ & $<0.001$ \\
\hline Religious & 200/591 (33.8) & 136/391 (34.8) & $64 / 200(32.0)$ & 0.498 \\
\hline \multicolumn{5}{|l|}{ Medication use } \\
\hline Lipid lowering & 40/591 (6.8) & 35/391 (8.9) & $5 / 200(2.5)$ & 0.003 \\
\hline Antidepressants & $39 / 591(6.6)$ & 14/391 (3.6) & $25 / 200(12.5)$ & $<0.001$ \\
\hline Blood pressure medications & $36 / 591(6.1)$ & 26/391 (6.6) & $10 / 200(5.0)$ & 0.427 \\
\hline Thyroid replacement therapy & $34 / 591(5.8)$ & $12 / 391(3.1)$ & $22 / 200(11.0)$ & $<0.001$ \\
\hline Aspirin/anticoagulants & $30 / 391(5.1)$ & 26/391 (6.6) & $4 / 200(2.0)$ & 0.003 \\
\hline Pain medications & 19/591 (3.2) & 11/391 (2.8) & $8 / 200(4.0)$ & 0.465 \\
\hline Asthma/allergy & 19/591 (3.2) & 10/391 (2.6) & $9 / 200(4.5)$ & 0.223 \\
\hline Other $^{\mathrm{a}}$ & 18/591 (3.0) & $11 / 391(2.8)$ & $7 / 200(3.5)$ & 0.622 \\
\hline OC/hormone replacement therapy & 10/591 (1.7) & $0 / 391(0.0)$ & 10/200 (5.0) & N/A \\
\hline BPH medications/sildenafil & $5 / 591(0.8)$ & $5 / 391(1.3)$ & $0 / 200(0.0)$ & N/A \\
\hline Arrhythmia drugs & $3 / 591(0.5)$ & $2 / 391(0.5)$ & $1 / 200(0.5)$ & 1.000 \\
\hline
\end{tabular}

Values are mean \pm SD or $n$ (\%); $p$ values reflect significance of difference between men and women $\mathrm{BPH}$ benign prostatic hyperplasia, $\mathrm{OC}$ oral contraceptive, N/A not applicable

Includes allopurinol, antiseizure, biologics, and immunosuppressants

older $(51 \pm 9$ vs. $48 \pm 9$ years, $p<0.001)$ and were more likely to be married or in a committed monogamous relationship ( 89 vs. $71 \%, p<0.001$ ). Of the participants, $34 \%(201 / 591)$ used $\geq 1$ prescription medication on a daily basis. The most commonly used medications included lipid lowering agents (used by $8.9 \%$ of men, $2.5 \%$ of women; $p=0.003$ ), antidepressants (used by $3.6 \%$ of men, $12.5 \%$ of women; $p<0.001$ ), antihypertensives (used by $6.6 \%$ of men, $5.0 \%$ of women; $p=0.427$ ), thyroid replacement therapy (used by $3.1 \%$ of men, $11.0 \%$ of women; $p<0.001$ ), and anticoagulants including aspirin (used by $6.6 \%$ of men, $2.0 \%$ of women; $p=$ 0.003).

\section{Exercise Exposure and Lifestyle Habits}

Lifestyle habits and exercise exposure history are shown in Table 2. Participants reported $21.3 \pm 12.9$ years of prior participation in competitive endurance sports. Cycling was the most common primary sport among men while running was the most common primary sport among women. Participants reported $10 \pm 6$ h of weekly total exercise training of which approximately $60 \%$ was dedicated to their primary sport. Active tobacco use was rare (men $2 / 391,<1 \%$; females $1 / 200,<1 \% ; p=0.73$ ), but $23 \%$ were prior tobacco users. Compared to women, men drank more alcohol on a weekly basis and were more likely to have been told by a friend or a peer that their alcohol consumption was problematic. Finally, approximately one in six participants adhered to some form of macronutrient dietary restriction, and the majority $($ men $=68 \%$, women $=74 \% ; p=0.152)$ reported routinely using diet to control weight.

\section{Healthcare Utilization and Satisfaction}

Data describing healthcare utilization and satisfaction are shown in Table 3. Approximately three quarters of the sample reported attending visits to a primary care physician on an annual basis (men $=75 \%$ vs. women = $79 \%, p=0.302$ ), and approximately one third of the sample had received care from a CV specialist on at least one occasion $(\mathrm{men}=38 \%$ vs. women $=24 \%, p<0.001)$. Exposure to prior $\mathrm{CV}$ diagnostic testing is shown in Fig. 2. Among men, $63 \%$ reported having undergone at least one prior CV test compared with a $45 \%$ test exposure rate among women $(p<0.001)$. Twelve-lead electrocardiography was the most commonly utilized test 
Table 2 Lifestyle habits, exercise exposure, and dietary preferences

\begin{tabular}{|c|c|c|c|c|}
\hline & Total & Men & Women & $p$ value \\
\hline Participation in endurance sports, years & $21.3 \pm 132.9$ & $22.4 \pm 13.3$ & $19.2 \pm 121.6$ & 0.003 \\
\hline Participation in high school sport & $441 / 591(74.6)$ & $306 / 391(78.3)$ & $135 / 200(67.5)$ & 0.004 \\
\hline Participation in college sport & 282/591 (47.7) & 204/391 (52.2) & 78/200 (39.0) & 0.002 \\
\hline \multicolumn{5}{|l|}{ Current primary sport } \\
\hline Cycling & 246/591 (41.6) & 201/391 (51.4) & $45 / 200(22.5)$ & $<0.001$ \\
\hline Running & $147 / 591(24.9)$ & 76/391 (19.4) & $71 / 200(35.5)$ & $<0.001$ \\
\hline Swimming & $72 / 591(12.2)$ & 33/391 (8.4) & $39 / 200(19.5)$ & $<0.001$ \\
\hline Triathlon & $54 / 591(9.1)$ & 33/391 (8.4) & $21 / 200(10.5)$ & 0.411 \\
\hline Rowing & $56 / 591(9.5)$ & $38 / 391(9.7)$ & 18/200 (9) & 0.778 \\
\hline Other ${ }^{a}$ & 11/591 (1.9) & $7 / 391(1.8)$ & $4 / 200(2.0)$ & $<0.001$ \\
\hline Current total training, h/week & $10.3 \pm 5.5$ & $10.1 \pm 4.5$ & $10.6 \pm 7.1$ & 0.298 \\
\hline \multicolumn{5}{|l|}{ Weekly training breakdown, avg. h/week } \\
\hline Primary sport & $6.5 \pm 4.4$ & $6.8 \pm 4.0$ & $6.1 \pm 5.3$ & 0.111 \\
\hline Alternative endurance activity & $1.9 \pm 2.6$ & $1.6 \pm 2.1$ & $2.6 \pm 3.4$ & $<0.001$ \\
\hline Strength training & $0.6 \pm 1.0$ & $0.6 \pm 0.9$ & $0.8 \pm 1.1$ & 0.027 \\
\hline Other ${ }^{a}$ & $0.5 \pm 1.3$ & $0.4 \pm 1.1$ & $0.7 \pm 1.6$ & 0.029 \\
\hline \multicolumn{5}{|l|}{ Tobacco exposure } \\
\hline Former smoker & $134 / 591(22.7)$ & 87/391 (23.8) & $47 / 200(25.5)$ & 0.731 \\
\hline Current smoker & $3 / 591(0.5)$ & 2/391 (0.5) & $1 / 200(0.5)$ & 1.000 \\
\hline \multicolumn{5}{|l|}{ Alcohol consumption } \\
\hline Total number of drinks/week & $4.7 \pm 4.8$ & $5.3 \pm 5.2$ & $3.7 \pm 3.9$ & $<0.001$ \\
\hline Number of nights/week with $\geq 1$ drink & $2.7 \pm 2.4$ & $2.9 \pm 2.4$ & $2.4 \pm 2.3$ & 0.015 \\
\hline Personal/peer concern about over-drinking & 94/591 (15.9) & 72/391 (18.4) & 22/200 (11.0) & 0.020 \\
\hline \multicolumn{5}{|l|}{ Dietary habits } \\
\hline Routinely use diet to control weight & $412 / 591(69.7)$ & 265/391 (67.8) & $147 / 200(73.5)$ & 0.152 \\
\hline Follow strict diet ${ }^{\mathrm{b}}$ & $103 / 591(17.4)$ & 63/391 (16.1) & $40 / 200(20.0)$ & 0.239 \\
\hline
\end{tabular}

Values are mean \pm SD or $n(\%) ; p$ values reflect significance of difference between men and women

${ }^{a}$ Includes boot camp, P90X, weight training, and yoga

${ }^{b}$ Includes gluten-free, lactose-free, and paleo diet, vegan, and vegetarian

followed in decreasing order by exercise stress testing, transthoracic echocardiography, and cardiac CT scanning. For each of these testing modalities, rates of prior testing exposure were higher for men than women.

Indices reflecting satisfaction with the healthcare system are shown in Table 3. We observed an overall rate of healthcare system dissatisfaction of approximately $14 \%$. Among participants who reported dissatisfaction, the most common reasons for dissatisfaction included (1) presenting concerns dismissed due to status as an athlete (21\%), (2) inadequate time and/or attention paid during clinical visits (10\%), and (3) inadequate knowledge among care providers of issues specific to athletes (10\%).

\section{Cardiovascular Disease Risk Factors}

The prevalence of CV disease risk factors is detailed in Table 4. A significant family history of atherosclerosis
(32\% of respondents) and prior tobacco use (23\% of respondents) were the most commonly reported risk factors. Hypertension $(\operatorname{men}=15 \%$ vs. women $=6 \%$, $p=0.001)$ and dyslipidemia ( $m e n=10 \%$ vs. women $=$ $3 \%, p=0.001$ ) were more common among men than women. Notably, only $27 \%$ of MAs were completely free of $\mathrm{CV}$ risk factors while roughly two thirds had one or more asymptomatic risk factors as shown in Fig. 3.

\section{Established Cardiovascular Disease}

The prevalence of established CV disease was $9 \%$ (54/ 591) among this community-based cohort of MAs. Arrhythmia (26/591, 4.4\%), accounted for almost exclusively by AF (24/26 cases), and atherosclerosis (16/591, $2.7 \%$ ), accounted for exclusively by CAD, were the two most common conditions and were similarly prevalent 
Table 3 Healthcare utilization and satisfaction

\begin{tabular}{|c|c|c|c|c|}
\hline & Total & Men & Women & $p$ value \\
\hline Regularly visit a PCP & $452 / 591(76.5)$ & 294/391 (75.2) & $158 / 200(79.0)$ & 0.302 \\
\hline$\geq 1$ visit to a cardiologist & 195/591 (33.0) & 148/391 (37.9) & $47 / 200(23.5)$ & $<0.001$ \\
\hline$\geq 1$ visit to a sports med specialist & $353 / 591(59.7)$ & 230/391 (58.8) & $123 / 200(61.5)$ & 0.530 \\
\hline$\geq 1$ visit to a nutritionist & $113 / 591(19.1)$ & $57 / 391(14.6)$ & $56 / 200(28.0)$ & $<0.001$ \\
\hline Dissatisfied with current healthcare & $80 / 591(13.5)$ & 49/391 (12.5) & $31 / 200(15.5)$ & 0.318 \\
\hline \multicolumn{5}{|l|}{ Provider type responsible for dissatisfaction } \\
\hline Primary care provider & $60 / 80(75.0)$ & $36 / 49(73.5)$ & 24/31 (77.4) & 0.794 \\
\hline Subspecialist & $9 / 80(11.3)$ & $5 / 49(10.2)$ & 4/31 (12.9) & 0.729 \\
\hline Nonphysician provider & $3 / 80(3.8)$ & $3 / 49(6.1)$ & $0 / 31(0)$ & 0.279 \\
\hline Other & $8 / 80(10.0)$ & $5 / 49(10.2)$ & $3 / 31(9.7)$ & 1.000 \\
\hline \multicolumn{5}{|l|}{ Primary reason for dissatisfaction } \\
\hline Concerns dismissed due athlete status & $17 / 80(21.3)$ & $7 / 49(14.3)$ & $10 / 31(3.2)$ & 0.091 \\
\hline Not enough time/attention paid & $8 / 80(10.0)$ & $8 / 49(16.3)$ & $0 / 31(0)$ & N/A \\
\hline Minimal knowledge of athlete issues & $8 / 80(10.0)$ & $8 / 49(16.3)$ & $0 / 31(0)$ & N/A \\
\hline Cost & $7 / 80(8.8)$ & $5 / 49(10.2)$ & $2 / 31(6.5)$ & 0.700 \\
\hline Access & $7 / 80(8.8)$ & 4/49 (8.2) & $3 / 31(9.7)$ & 1.000 \\
\hline Misdiagnosis/no resolution of problem & $6 / 80(7.5)$ & $2 / 49(4.1)$ & $4 / 31(12.9)$ & 0.200 \\
\hline Prescribed med impaired performance & $5 / 80(6.3)$ & $3 / 49(6.1)$ & 2/31 (6.5) & 1.000 \\
\hline Counseled to reduce exercise & $5 / 80(6.3)$ & $4 / 49(8.2)$ & $1 / 31(3.2)$ & 0.644 \\
\hline Counseled to terminate exercise & $4 / 80(5.0)$ & 2/49 (4.1) & $2 / 31(6.5)$ & 0.639 \\
\hline Not indicated & $13 / 80(16.3)$ & $6 / 49(12.2)$ & $7 / 31(22.6)$ & 0.234 \\
\hline
\end{tabular}

Values are $n(\%) ; p$ values reflect significance of difference between men and women

among men and women. The results of logistic regression analyses used to identify factors associated with arrhythmia and CAD are shown in Table 5. In multivariate logistic regression models controlling for age, cumulative years of exercise exposure $[\mathrm{OR}=1.10(1.06,1.21)]$ and hypertension $[\mathrm{OR}=1.05(1.01,1.10)]$ were independently associated with the presence of $\mathrm{AF}$, while in contrast, dyslipidemia $[\mathrm{OR}=9.09(2.40,34.39)]$ and prior tobacco use $[\mathrm{OR}=1.78(1.34,3.10)]$ were independently associated with prevalent CAD.

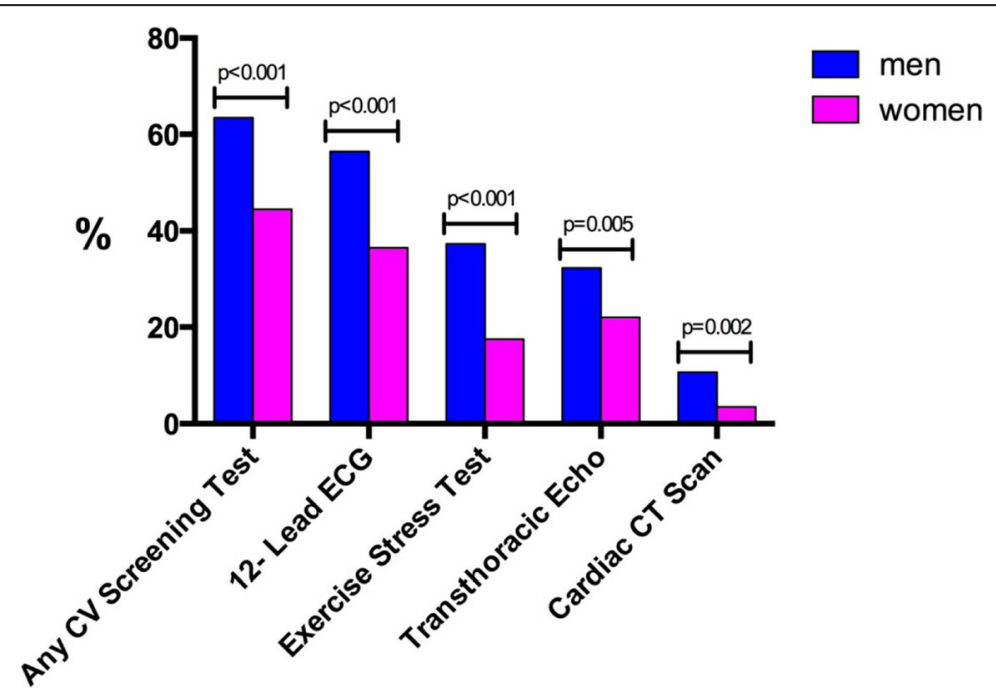

Fig. 2 Prior exposure to cardiovascular screening/diagnostic tests. Among respondents, men underwent significantly more CV screening tests than women both in total and across the four different testing modalities. CT computed tomography, ECG electrocardiography 
Table 4 Prevalence of traditional CV risk factors and established CV disease

\begin{tabular}{|c|c|c|c|c|}
\hline & Total & Men & Women & $p$ value \\
\hline \multicolumn{5}{|l|}{$\mathrm{CV}$ risk factors } \\
\hline Family history of atherosclerosis & 189/591 (32.0) & 120/391 (30.7) & $69 / 200(34.5)$ & 0.347 \\
\hline Former/current smoker & 137/591 (23.2) & 89/391 (22.7) & $48 / 200(24)$ & 0.736 \\
\hline Hypertension & $71 / 591(12.0)$ & 59/391 (15.1) & $12 / 200(6.0)$ & 0.001 \\
\hline Dyslipidemia & 44/591 (7.4) & 38/391 (9.7) & $6 / 200(3.0)$ & 0.003 \\
\hline Obesity & 17/591 (2.9) & 14/391 (3.6) & $3 / 200(1.5)$ & 0.58 \\
\hline Diabetes mellitus & 2/591 (0.3) & 2/391 (0.5) & $0 / 200(0.0)$ & N/A \\
\hline Aggregate CV disease & $54 / 591(9.1)$ & 40/391 (10.7) & $14 / 200(8.0)$ & 0.237 \\
\hline Arrhythmia & $26 / 54(48.1)$ & $21 / 40(52.5)$ & $5 / 14(35.7)$ & 0.358 \\
\hline Atherosclerosis & 16/54 (29.6) & $13 / 40(32.5)$ & $3 / 14(21.4)$ & 0.516 \\
\hline Valvular & 10/54 (18.5) & $4 / 40(10.0)$ & $6 / 14(42.9)$ & 0.013 \\
\hline Other $^{\mathrm{a}}$ & $2 / 54(3.7)$ & $2 / 40(5.0)$ & 0/14 (0.0) & N/A \\
\hline
\end{tabular}

Values are $n$ (\%); $p$ values reflect significance of difference between men and women

CV cardiovascular

ancludes one case of pericarditis and one case of atrial septal defect

\section{Discussion and Conclusions}

The Boston MASTER study was conducted to develop a comprehensive CV profile of the contemporary MA. Key findings from this study, a characterization of men and women with more than 20 years of competitive endurance sport exposure who at the time of this study were completing approximately four times the amount of physical exercise recommended for health optimization [11], can be summarized as follows. First, $64 \%$ of this population had at least one established CV risk factor with a family history of premature atherosclerotic disease and prior tobacco exposure identified as the most common issues. Second, there was a $9 \%$ prevalence of established CV disease that was accounted for almost exclusively by AF and CAD. Third, roughly one in seven MAs reported overall dissatisfaction with the healthcare system due in part to care providers' tendency to dismiss complaints due to their status as athletes. Finally, our data shed important insights into CV disease characteristics among MAs. Specifically, prevalence of AF appears to be associated with years of cumulative exercise exposure and concomitant hypertension, while in contrast, CAD appears to be associated with traditional atherosclerotic risk factors (i.e., hypertension, dyslipidemia) and negligibly associated with any element of prior exercise exposure.

Routine low to moderate intensity physical exercise leads to favorable changes in CV risk factors [12-14] and is recommended for both the primary and secondary prevention of CV disease [11]. However, the dose response relationship between exercise and CV outcomes remains incompletely understood, and there is mounting evidence that people who engage in high levels of exercise may be surprisingly susceptible to specific forms of heart disease including AF [7], coronary atherosclerosis
[6], and myocardial fibrosis [15]. In addition, two recent observational population-based studies suggest that the mortality benefits afforded by physical activity may dissipate among people who engage in the highest levels of exercise [16, 17]. Definitive explanations for these intriguing observations remain speculative, in part because studies aimed at examining the people who engage in the highest levels of exercise have been lacking. Findings from this study present a comprehensive social and CV medical profile for this segment of the population and shed novel insights into why high-level exercisers may be susceptible to common forms of heart disease.

Our data support the notion that AF is the most common acquired $\mathrm{CV}$ condition among MAs and complement recent work demonstrating an association between duration of participation in competitive athletic and susceptibility to arrhythmia [7, 18]. In addition, we now demonstrate that concomitant hypertension is independently associated with prevalent AF. Future prospective interventional studies will be required to determine whether aggressive blood pressure control will lead to a reduced burden of AF among chronic high-level exercisers. Unlike AF, we detected no associations between atherosclerotic CAD and exercise exposure. This finding was somewhat surprising following recent reports of increased CAD among seasoned marathon runners $[5,6]$. While we cannot exclude the possibility that high-level exercise plays a role in the progression of atherosclerosis, our data suggest that the presence and perhaps undertreatment of traditional atherosclerotic risk factors are a far more powerful determinant of CAD risk. This finding helps to explain why CAD occurs among seasoned exercisers and simultaneously provides opportunities to improve primary prevention efforts in clinical 
a

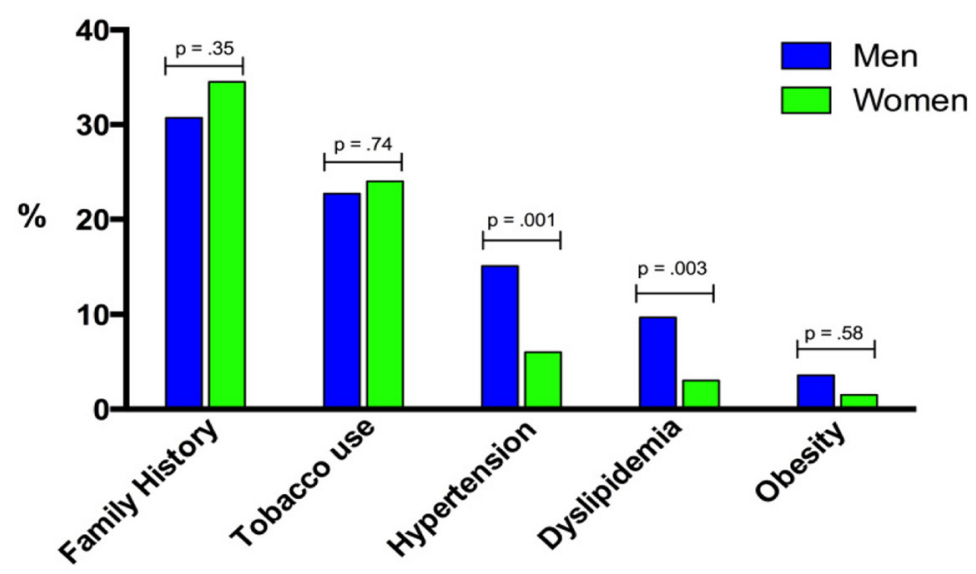

Distribution of Traditional CV Risk Factors Burden
and Established CV Disease Among Masters Athletes

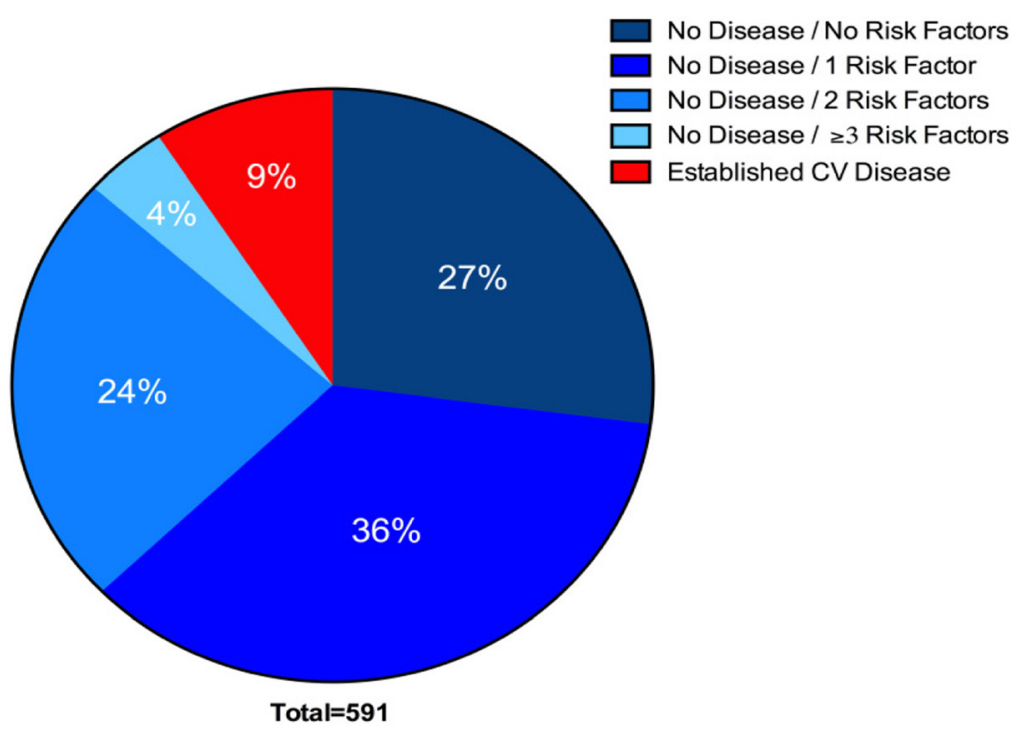

Fig. 3 a Prevalence of traditional cardiovascular risk factors and $\mathbf{b}$ distribution of risk factor burden and disease prevalence. a Significant family history of atherosclerosis and prior/current tobacco exposure were the most common CV risk factors among male and female MAs. Men had significantly higher rates of hypertension and dyslipidemia, as compared to women. $\mathbf{b}$ Graphical representation of the survey population stratified by risk factor and disease burden. Of this population, $64 \%$ reported at least one cardiovascular risk factor while the overall prevalence of established CV disease was $9 \%$. CAD coronary artery disease

practice including the targeted treatment of modifiable atherosclerotic risk factors.

Existing data examining CV risk factor prevalence among competitive MAs are sparse. De Matos et al. reported age-dependent increases in the rates of abnormal lipid profiles, body mass index, and fasting glucose among 247 Brazilian MAs [19]. Risk factor prevalence data from the present study builds on this prior work in several important ways. The nontrivial rates of hypertension (12.4\%), dyslipidemia (7.4\%), and obesity ( $2.9 \%)$ observed among this current cohort of MAs are substantially lower than those recently reported in the general population [20]. Thus, long-term dedication to high levels of exercise may substantially reduce the burden of these disease determinants but does not appear to eliminate them completely. In contrast, the rate of tobacco exposure observed in our cohort of MAs is similar to that reported in the general population. Our finding that prior tobacco exposure was an independent risk factor for CAD indicates that it is a significant source of morbidity among MAs. While 
Table 5 Univariate and multivariate logistic regression analyses demonstrating factors associated with established arrhythmia and coronary artery disease

\begin{tabular}{|c|c|c|c|c|}
\hline & Arrhythmia $(n=26)$ & & Coronary artery dis & \\
\hline & Univariate analysis & Multivariate analysis & Univariate analysis & Multivariate analysis \\
\hline & OR $(95 \% \mathrm{Cl})$ & OR $(95 \% \mathrm{Cl})$ & OR $(95 \% \mathrm{Cl})$ & OR $(95 \% \mathrm{Cl})$ \\
\hline Age & $1.07(1.02,1.12)$ & $1.06(1.00,1.11)$ & $1.08(1.02,1.15)$ & $1.06(1.01,1.14)$ \\
\hline Male gender & $2.07(0.68,6.35)$ & - & $2.46(0.53,11.5)$ & - \\
\hline Years exercise exposure & $1.14(1.08,1.27)$ & $1.10(1.06,1.21)$ & $1.01(0.97,1.06)$ & - \\
\hline Exercise (h/week) & $1.01(0.94,1.08)$ & - & $0.99(0.87,1.12)$ & - \\
\hline Alcohol (drinks/week) & $1.26(1.09,1.93)$ & - & $0.94(0.80,1.09)$ & - \\
\hline Prior/active tobacco use & $1.08(0.97,1.18)$ & - & $3.56(1.35,5.78)$ & $1.78(1.34,3.10)$ \\
\hline Family history & $0.79(0.28,2.23)$ & - & $2.75(0.83,9.16)$ & - \\
\hline Hypertension & $1.07(1.02,1.12)$ & $1.05(1.01,1.10)$ & $1.08(1.02,1.15)$ & - \\
\hline Dyslipidemia & $1.95(0.54,6.99)$ & - & $13.92(4.04,47.91)$ & $9.09(2.40,34.39)$ \\
\hline
\end{tabular}

speculative, it is likely that some older athletes adopt a high-level exercise lifestyle following years of previous risk exposure in an attempt to offset previous high-risk lifestyle choices. Clinical characterization of overall risk and future studies geared toward delineating disease pathogenesis in this population should take measures to address this issue.

To our knowledge, healthcare utilization and satisfaction have not been previously characterized among MAs. It is noteworthy that approximately one in four of our study participants did not receive routine primary care. This finding, coupled with the observed prevalence of both risk factors and disease, suggests a need for more effective public health outreach campaigns that should be designed to complement current screening recommendations for this specific population $[3,21]$. Among those athletes who were engaged in the healthcare system, one third had received care from a CV specialist and $63 \%$ had been subjected to one or more forms of $\mathrm{CV}$ diagnostic testing. These findings highlight the need for CV clinicians to be familiar with the unique characteristics of this population and emphasize the importance of developing MA-specific algorithms for the implementation and interpretation of CV testing. Optimal care of aging athletes may best be accomplished through a partnership between sports medicine physicians and $\mathrm{CV}$ specialists with expertise in the care of athletes. Finally, we observed a rate of overall healthcare dissatisfaction of $14 \%$ with several underlying explanations that are unique to this population. Specifically, participants reported dissatisfaction due to (1) having their concerns dismissed due to their status as ostensibly healthy athletes and (2) inadequate knowledge among care providers about issues specific to athletes. These reasons for dissatisfaction indicate a previously unrecognized form of patient-provider mismatch that may be addressed by refinements in clinical training and further development of sports cardiology as an established area of expertise.
We acknowledge several limitations of this study. Data acquisition was performed using an Internet-based survey, and therefore, several potential sources of error must be addressed [22]. We sought to minimize the impact of nonresponse error by excluding all data derived from surveys that were less than $95 \%$ complete. Similarly, we sought to minimize the likelihood of inaccurate response data by utilizing concise and clearly worded survey questions coupled with very specific trait definitions of cardiac risk factors and disease to reduce the impact of measurement error. As we studied MAs from a relatively confined geographic area, we acknowledge the possibility of coverage error that may limit the generalizability of our results to MAs in other locations. Similarly, we are unable to exclude some element of sampling error as our data reflect voluntary survey participation and it is possible that respondents on either end of the health spectrum were more or less likely to participate. However, we attempted to reduce sampling bias by advertising this survey as a general exercise and lifestyle study, thereby minimizing selection as a function of health status, and made our survey available to a large unselected group of potential participants. Finally, given the observational and cross-sectional nature of our data and the relatively low incidence of established disease, we are unable to determine the clinical significance and modifiability of the reported ORs.

People including MAs who engage in high levels of routine physical exercise are not completely protected from $\mathrm{CV}$ disease. AF and CAD have emerged as important sources of morbidity and mortality in this segment of the population and appear to be associated with distinctly different determinants of disease pathogenesis. Widespread recognition of disease-specific risk profiles coupled with targeted therapeutic efforts among MAs may hold value for preventing the development of $\mathrm{CV}$ disease in this population. 


\section{Funding}

No active or past funding is directly relevant to this study. Dr. Baggish is supported by research grants from the National Institutes of Health (RO1 DA029141, RO1 HL117037, RO1 HL125869).

\section{Authors' Contributions}

$\mathrm{KS}, J \mathrm{D}, \mathrm{MC}$, and ALB participated in the study design, data collection, data analysis, manuscript preparation, and critical manuscript revisions. MW, RBW, $\mathrm{GDL}$, and AH participated in manuscript preparation and critical manuscript revisions. All authors read and approved the final manuscript.

\section{Competing Interest}

Kayle Shapero PhD declares that she has no conflict of interest. James Deluca BS declares that he has no conflict of interest. Miranda Contursi MS declares that she has no conflict of interest. Meagan Wasfy MD declares that she has no conflict of interest. Rory B. Weiner MD declares that he has no conflict of interest. Gregory D. Lewis MD declares that he has no conflict of interest. Adolph Hutter MD declares that he has no conflict of interest. Aaron L. Baggish MD declares that he has no conflict of interest.

\section{Ethics Approval and Consent to Participate}

All aspects of the survey, recruitment protocol, and analytic plan were approved by the Partner's Human Research Committee. The study complied with the Declaration of Helsinki, and informed consent was obtained from each subject prior to beginning the survey.

\section{Author details}

${ }^{1}$ Tufts University School of Medicine, Boston, MA, USA. ${ }^{2}$ Cardiovascular Performance Program, Massachusetts General Hospital, 55 Fruit Street, Yawkey Suite 5B, Boston, MA 02114, USA

Received: 23 February 2016 Accepted: 20 July 2016

Published online: 09 August 2016

\section{References}

1. Thompson PD, Funk EJ, Carleton RA, Sturner WQ. Incidence of death during jogging in Rhode Island from 1975 through 1980. JAMA. 1982:247(18):2535-8.

2. Siscovick DS, Weiss NS, Fletcher RH, Lasky T. The incidence of primary cardiac arrest during vigorous exercise. N Engl J Med. 1984;311(14):874-7.

3. Maron BJ, Araujo CG, Thompson PD, Fletcher GF, de Luna AB, Fleg JL, et al. Recommendations for preparticipation screening and the assessment of cardiovascular disease in masters athletes: an advisory for healthcare professionals from the working groups of the World Heart Federation, the International Federation of Sports Medicine, and the American Heart Association Committee on Exercise, Cardiac Rehabilitation, and Prevention. Circulation. 2001:103(2):327-34

4. Kim JH, Malhotra R, Chiampas G, d'Hemecourt P, Troyanos C, Cianca J, et al. Cardiac arrest during long-distance running races. N Engl J Med. 2012; 366(2):130-40.

5. Schwartz RS, Merkel Kraus S, Schwartz JG, Wickstrom KK, Peichel G, Garberich RF, et al. Increased coronary artery plaque volume among male marathon runners. Mo Med. 2014;111(2):85-90.

6. Mohlenkamp S, Lehmann N, Breuckmann F, Brocker-Preuss M, Nassenstein $K$, Halle $M$, et al. Running: the risk of coronary events: prevalence and prognostic relevance of coronary atherosclerosis in marathon runners. Eur Heart J. 2008;29(15):1903-10

7. Andersen K, Farahmand B, Ahlbom A, Held C, Ljunghall S, Michaelsson K, et al. Risk of arrhythmias in 52755 long-distance cross-country skiers: a cohort study. Eur Heart J. 2013:34(47):3624-31.

8. La Gerche A, Burns AT, Mooney DJ, Inder WJ, Taylor AJ, Bogaert J, et al. Exercise-induced right ventricular dysfunction and structural remodelling in endurance athletes. Eur Heart J. 2011;epub December 6, 2011.

9. Chobanian AV, Bakris GL, Black HR, Cushman WC, Green LA, Izzo Jr JL, et al. The seventh report of the Joint National Committee on Prevention, Detection, Evaluation, and Treatment of High Blood Pressure: the JNC 7 report. JAMA. 2003:289(19):2560-72

10. National Cholesterol Education Program Expert Panel on Detection E, Treatment of High Blood Cholesterol in A. Third report of the National Cholesterol Education Program (NCEP) Expert Panel on Detection, Evaluation, and Treatment of High Blood Cholesterol in Adults (Adult Treatment Panel III) final report. Circulation. 2002;106(25):3143-421.
11. Haskell WL, Lee IM, Pate RR, Powell KE, Blair SN, Franklin BA, et al. Physical activity and public health: updated recommendation for adults from the American College of Sports Medicine and the American Heart Association. Circulation. 2007:116(9):1081-93.

12. Kraus WE, Houmard JA, Duscha BD, Knetzger KJ, Wharton MB, McCartney JS, et al. Effects of the amount and intensity of exercise on plasma lipoproteins. N Engl J Med. 2002;347(19):1483-92.

13. Duncan JJ, Farr JE, Upton SJ, Hagan RD, Oglesby ME, Blair SN. The effects of aerobic exercise on plasma catecholamines and blood pressure in patients with mild essential hypertension. JAMA. 1985;254(18):2609-13.

14. Irwin ML, Yasui Y, Ulrich CM, Bowen D, Rudolph RE, Schwartz RS, et al. Effect of exercise on total and intra-abdominal body fat in postmenopausal women: a randomized controlled trial. JAMA. 2003;289(3):323-30.

15. La Gerche A, Burns AT, Mooney DJ, Inder WJ, Taylor AJ, Bogaert J, et al. Exercise-induced right ventricular dysfunction and structural remodelling in endurance athletes. Eur Heart J. 2012;33(8):998-1006.

16. Lee DC, Pate RR, Lavie CJ, Sui X, Church TS, Blair SN. Leisure-time running reduces all-cause and cardiovascular mortality risk. J Am Coll Cardiol. 2014 64(5):472-81.

17. Schnohr $P, O^{\prime}$ Keefe $J H$, Marott $J L$, Lange $P$, Jensen GB. Dose of jogging and long-term mortality: the Copenhagen City Heart Study. J Am Coll Cardiol. 2015:65(5):411-9.

18. Sorokin AV, Araujo CG, Zweibel S, Thompson PD. Atrial fibrillation in endurance-trained athletes. Br J Sports Med. 2011:45(3):185-8.

19. De Matos LD, Caldeira Nde A, Perlingeiro Pde S, dos Santos IL, Negrao CE, Azevedo LF. Cardiovascular risk and clinical factors in athletes: 10 years of evaluation. Med Sci Sports Exerc. 2011;43(6):943-50.

20. Mozaffarian D, Benjamin EJ, Go AS, Arnett DK, Blaha MJ, Cushman M, et al. Executive summary: heart disease and stroke statistics-2015 update: a report from the American Heart Association. Circulation. 2015;131(4):434-41.

21. Borjesson M, Urhausen A, Kouidi E, Dugmore D, Sharma S, Halle M, et al. Cardiovascular evaluation of middle-aged/senior individuals engaged in eisure-time sport activities: position stand from the sections of exercise physiology and sports cardiology of the European Association of Cardiovascular Prevention and Rehabilitation. Eur J Cardiovasc Prev Rehabil. 2011;18(3):446-58

22. Dillman DA, Smyth JD, Christian LM. Internet, phone, mail, and mixed-mode surveys: the Tailored Design Approach. 4th ed. Hoboken, New Jersey: Wiley; 2014

\section{Submit your manuscript to a SpringerOpen ${ }^{\circ}$ journal and benefit from:}

- Convenient online submission

- Rigorous peer review

- Immediate publication on acceptance

- Open access: articles freely available online

- High visibility within the field

Retaining the copyright to your article

Submit your next manuscript at springeropen.com 